\title{
Ligation of CD8 leads to apoptosis of thymocytes that have not undergone positive selection
}

\author{
Kristie M. Grebe, Raedun L. Clarke, and Terry A. Potter*
}

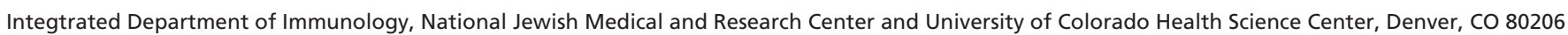

Edited by Philippa Marrack, National Jewish Medical and Research Center, Denver, CO, and approved May 27, 2004 (received for review March 24, 2004)

Thymocytes that are not positively selected are said to undergo "death by neglect." We have found that ligation of CD8, either by antibodies or MHC class I molecules, induces apoptosis of $\mathrm{CD}^{+}{ }^{+} \mathrm{CD} 8{ }^{+}$double-positive (DP) thymocytes. The susceptibility of thymocytes to CD8-mediated apoptosis is developmentally regulated and confined to a subpopulation of DP thymocytes. Stimulation through CD3 protects thymocytes from CD8-mediated apoptosis. We suggest that during thymocyte development, binding of CD8 to MHC class I molecules without T cell receptor engagement induces apoptosis in immature DP thymocytes. Our data are consistent with a model in which thymocytes that do not survive positive selection undergo "death by instruction" instead of death by neglect.

T cell development | thymus | MHC

$\mathbf{P}$ ositive and negative selection are mediated by the avidity/ affinity of the interactions between the $\mathrm{T}$ cell receptor (TCR) and MHC molecules (1-4). It is estimated that $\approx 90 \%$ of all thymocytes do not express a rearranged TCR $\alpha \beta$ complex capable of a low-affinity interaction with host MHC molecules, and self peptides fail positive selection and are eliminated. The mechanism by which cells that do not "pass" positive selection are removed is usually termed "death by neglect," Death by neglect has not been defined, but as the name implies, it is generally considered to result from a lack of cytokines or other growth factors delivered to the cell. The cytokines IL-2 and IL-7 up-regulate antiapoptotic proteins and enhance the survival of thymocytes (5-7). Death receptors most likely do not play a role in death by neglect because the expression of a dominantnegative FADD molecule in thymocytes has no effect on apoptosis caused by cytokine withdrawal (8). Steroids have also been implicated in thymocyte survival. Whereas adrenalectomized mice have increased thymic cellularity (9), mice reconstituted with bone marrow deficient in the expression of the glucocorticoid receptor have normal thymic cellularity and no apparent defects in death by neglect (10).

The stalk region of $\operatorname{CD} 8(\alpha$ and $\beta)$ contains a number of O-linked sugars (11) that undergo changes during the maturation of thymocytes. In particular, the O-linked carbohydrates on CD8 expressed by immature double-positive (DP) thymocytes are not sialylated (12). Accompanying the differentiation of DP thymocytes to CD8 single-positive (SP) cells, the sugar moieties on CD8 are extensively sialylated by the enzyme ST3Gal-I sialytransferase and become negatively charged (13). The nonsialylated form of CD8 on immature DP thymocytes has a higher affinity for MHC class I molecules and can bind MHC class I molecules in the absence of TCR-MHC class I interactions (14, 15). In contrast, there is no evidence that the affinity of CD4 for MHC class II molecule changes during thymocyte development.

Whether the changes in affinity of CD8 for MHC class I molecules during thymocyte development has a physiological role is unclear. Jameson and coworkers (15) suggested that an increase in the affinity of CD8 for MHC class I molecules may enhance positive selection by increasing the interaction between developing thymocytes and target cells. We have found that ligation of $\mathrm{CD} 8$ on a subpopulation of immature DP thymocytes, either with antibodies to CD8 or with MHC class I molecules, leads to rapid apoptosis. We have also found that treatment with antibodies to CD3 protects thymocytes from CD8-mediated apoptosis. We hypothesize that the binding of CD8 to MHC class I molecules on immature thymocytes, in the absence of TCR engagement, leads to the induction of apoptosis. This apoptotic stimulus may be a mechanism by which thymocytes that do not survive positive selection are removed.

\section{Materials and Methods}

Mice. $\mathrm{C} 57 \mathrm{BL} / 6$ and $\mathrm{B} 6 . \mathrm{MHC}^{-/-}\left(\mathrm{A} \beta \mathrm{b}^{-}\right.$and $\beta 2 \mathrm{M}^{-}$double knockout) mice were purchased from Taconic Farms. Young (4to 6-weeks old) mice were killed by $\mathrm{CO}_{2}$ asphyxiation. The thymus was removed and a single-cell suspension was prepared by passage through a $0.2-\mu \mathrm{m}$ cell strainer (Fisher) and resuspended in MEM plus 10\% FCS.

Crosslinking of CD8 with Antibodies. Thymocytes at $1 \times 10^{7}$ cells per $\mathrm{ml}$ were incubated with antibodies to either $\mathrm{CD} 8 \alpha$ (clone 53-6.7.2 or YTS169), CD4 (clone GK1.5), or CD8 $\beta$ (clone 53-5.8) at a final concentration of $10 \mu \mathrm{g} / \mathrm{ml}$ in a volume of 100 $\mu \mathrm{l}$ in individual wells of a flat bottom 96-well culture plate (Fisher). To crosslink the antibodies, $50 \mu \mathrm{g} / \mathrm{ml}$ goat anti-rat Ig (Jackson Immunolabs, West Grove, PA) was added to the cultures. As a positive control for apoptosis, cells were incubated with $1 \mu \mathrm{M}$ dexamethasone (Sigma). Cells were incubated at $37^{\circ} \mathrm{C}$ for 3-6 h, washed with PBS, and stained with annexin V-FITC (Biosource International, Camarillo, CA) and $0.5 \mu \mathrm{g} / \mathrm{ml}$ propidium iodide (PI; Sigma) and analyzed by flow cytometry.

Crosslinking of CD8 with Biotinylated Antibodies on Sorted Populations. C57BL $/ 6$ thymocytes were stained with antibodies to CD8 $\beta$ (allophycocyanin; Caltag, Burlingame, CA), CD4 (conjugated with Cychrome; Pharmingen) and phycoerythrinconjugated antibodies to either CD69 (eBioscience, San Diego), CD5 (eBioscience), or CD2 (eBioscience). Thymocytes that expressed $\mathrm{CD} 4, \mathrm{CD} 8 \beta$, and either high or low levels of CD2, CD5, or CD69 were collected on the Moflow cell sorter (Dakocytomation, Ft. Collins, CO). A total of $1 \times 10^{6}$ sorted thymocytes were incubated with biotinylated antibody to CD $8 \alpha$ (cloneYTS169) at a final concentration of $1 \mu \mathrm{g} / \mathrm{ml}$ and $2.5 \times 10^{5}$ streptavidin-coated microspheres (Spherotech, Libertyville, IL). These cultures were incubated at $37^{\circ} \mathrm{C}$ for $30 \mathrm{~min}$ and the cells stained with annexin V-FITC and PI as described above.

Ligation of CD8 with MHC Class I Molecules. Soluble TL, H-2K MHC class I molecules, mutant H-2K ${ }^{\mathrm{b}} \mathrm{Lys}-227 \mathrm{MHC}$ class I or class II molecules (IE ${ }^{\mathrm{k}}$ plus HB.27A peptide) were produced in High5 cells by using recombinant baculovirus and isolated by FPLC. Purified TL $/ \beta_{2} \mathrm{~m}, \mathrm{H}-2 \mathrm{~K}^{\mathrm{b}} / \beta_{2} \mathrm{~m}$, or $\mathrm{IE}^{\mathrm{k}}$ molecules were

This paper was submitted directly (Track II) to the PNAS office.

Abbreviations: DP, double-positive; SP, single-positive; PI, propidium iodide; PMA, phorbol myristate acetate; PS, phosphatidylserine; TCR, T cell receptor.

*To whom correspondence should be addressed. E-mail: pottert@njc.org.

C 2004 by The National Academy of Sciences of the USA 
biotinylated by using the BirA enzyme kit (Avidity, Denver). A total of $1 \mathrm{mg}$ of streptavidin-coated microspheres was incubated with $15 \mathrm{nmol}$ of soluble class I or class II MHC molecules overnight, and the excess MHC molecules were removed by centrifugation of the microspheres. When using $\mathrm{H}-2 \mathrm{~K}^{\mathrm{b}}$, the peptides SIINFEKL or FAPGNYPAL were added to stabilize the molecule. A total of $1 \times 10^{6}$ thymocytes and $1 \times 10^{6}$ microspheres coated with $\mathrm{TL}$ or $\mathrm{H}-2 \mathrm{~K}^{\mathrm{b}}$ were spun together, incubated as a pellet for $5 \mathrm{~min}$, and then gently resuspended and incubated at $37^{\circ} \mathrm{C}$ for $30 \mathrm{~min}$. Thymocyte populations isolated by sorting on the Moflow cell sorter as described above were also mixed with microspheres coated with TL in this manner. Cells were stained with annexin V-FITC and PI as above.

CD8 and CD3 Cocrosslinking. Thymocytes were incubated with biotinylated antibodies to CD8 (cloneYTS169) and either biotinylated antibody to CD3 (2c11) or biotinylated control antibody (R4GA2). All antibodies were used at a final concentration of $1 \mu \mathrm{g} / \mathrm{ml}$. A total of $1 \times 10^{6}$ cells were incubated with $5 \times 10^{5}$ streptavidin-coated microspheres at $37^{\circ} \mathrm{C}$ for $30 \mathrm{~min}$ and were then stained with annexin V-FITC and PI as described above.

Detection of Cytochrome $\boldsymbol{c}$ Release. Thymocytes were incubated with antibody to $\mathrm{CD} 8 \alpha$ and goat anti-rat $\mathrm{Ig}$ for $6 \mathrm{~h}$ at $37^{\circ} \mathrm{C}$ as described above and were then adhered to poly-D-lysine-coated coverslips, fixed with $3 \%$ formaldehyde in PBS, and permeabilized with $0.2 \%$ Triton X-100 in PBS $/ 0.02 \%$ azide. Cells were stained with an $\mathrm{mAb}$ to cytochrome $c$ (clone 6H2.B4; Pharmingen) and Cy3-conjugated anti-mouse Ig (Jackson Immunolabs). The cells were then mounted on slides with antifade mounting solution containing 4',6diamidino-2-phenylindole (Vector Laboratories) and analyzed on an Axioplan microscope (Zeiss) fitted with a xenon light source (OptiQuip, Highland Mills, NY) and a Sensicam charge-coupled device camera (Cooke, Auburn Hills, MI). Images were captured and analyzed by using SLIDEBOOK software (Intelligent Imaging Innovations, Denver).

Detection of DNA Fragmentation. Thymocytes were incubated with antibody to CD8 $\alpha$ (YTS169) and goat anti-rat Ig for $6 \mathrm{~h}$ and were fixed in ethanol overnight. The cells were then stained with 69 $\mu \mathrm{M}$ PI in PBS containing $10 \mu \mathrm{g} / \mathrm{ml}$ RNaseA (Sigma) and were analyzed by flow cytometry.

\section{Results}

Antibody Crosslinking of CD8 Induces Apoptosis of Thymocytes. Thymocytes from $\mathrm{MHC}^{-/-}$mice do not undergo positive selection and are arrested at the DP stage. Incubation of thymocytes from $\mathrm{MHC}^{-/-}$mice with antibodies to either $\mathrm{CD} 8 \alpha$ or $\mathrm{CD} 8 \beta$ crosslinked with goat anti-rat Ig for $6 \mathrm{~h}$ induced the exposure of phosphatidylserine (PS) on the outer leaflet of the cell membrane as measured by the binding of annexin V-FITC. Approximately $30 \%$ of the cells treated with antibodies to CD $8 \alpha$ or $\beta$ became apoptotic, as indicated by the binding of annexin V (Fig. 1). The rate of apoptosis initiated by antibody to CD8 and goat anti-rat Ig was rapid over the first $4-6 \mathrm{~h}$ and then declined to a rate similar to that observed in the cultures without antibody (data not shown). Two different antibodies to CD8 $\alpha, 53.6 .7$, and YTS 169, induced similar levels of apoptosis (data not shown). Treatment with dexamethasone, a potent inducer of apoptosis in thymocytes, also induced PS exposure in $\approx 50 \%$ of the cells after $6 \mathrm{~h}$ in culture (Fig. 1). Interestingly, treatment with antibody to CD4 under crosslinking conditions did not increase exposure of PS compared with the untreated cultures.

A similar amount of apoptosis $(30 \%)$ was obtained with biotinylated antibody to $\mathrm{CD} 8 \alpha$ crosslinked with streptavidincoated microspheres (data not shown). Interestingly, when these streptavidin-coated microspheres were used as the crosslinking reagent, apoptosis was very rapid, and within $30 \mathrm{~min}$, the
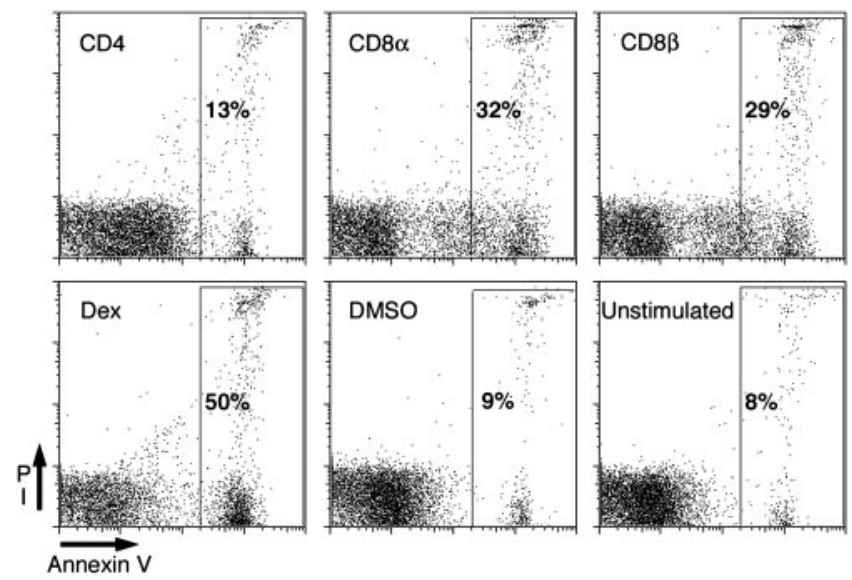

Fig. 1. Antibody crosslinking of $C D 8$, but not $C D 4$, induces annexin $V$ binding on a subset of thymocytes. Thymocytes from $\mathrm{MHC}^{-1-}$ mice were treated with antibodies to either $\mathrm{CD} 4, \mathrm{CD} 8 \alpha$, or $\mathrm{CD} 8 \beta$ and goat anti-rat Ig, dexamethasone, DMSO, or were left untreated (as indicated in the top left corner of the plot) for $6 \mathrm{~h}$. Cells were stained with FITC-conjugated annexin V and PI. Annexin V binding is shown on the $x$ axis, and PI staining is shown on the $y$ axis. In each plot, the percentage of cells in the gate is given.

percentage of apoptotic cells was similar to that obtained with crosslinking with anti-Rat IgG for 4-6 h. After $30 \mathrm{~min}$, the rate of apoptosis was similar to that observed in the absence of antibody. This difference in the kinetics of apoptosis induction observed with the two different methods of crosslinking the CD8 antibody may be due to the difference in the ability of each condition to achieve a high degree of crosslinking. The streptavidin-coated microspheres are likely able to achieve a higher degree of crosslinking than that of the goat anti-rat Ig. Overall, these observations suggested that antibody-mediated crosslinking of $\mathrm{CD} 8$, but not CD4, initiates an apoptotic pathway in thymocytes.

To confirm that crosslinking of CD8 was inducing apoptosis and not simply exposure of PS, other hallmark features of apoptosis were examined. Cytochrome $c$ release from the mitochondria can be monitored by the loss of discrete areas of staining within the cell. DNA fragmentation can be measured by the appearance of a population of cells having less than normal diploid DNA content (2N DNA). Antibody-mediated crosslinking of CD8 resulted in the release of cytochrome $c$ and fragmented DNA. Thymocyte cultures treated with antibodies to CD8 contained cells that did not exhibit staining of cytochrome $c$ and had small, condensed nuclei (Fig. $6 B$, which is published as supporting information on the PNAS web site). Antibody ligation of CD8 for $6 \mathrm{~h}$ also resulted in DNA fragmentation in $\approx 20 \%$ of thymocytes (Fig. $6 C$ ). This number is less than the number of cells expressing PS at the same time point and is most likely due to differences in the kinetics of the two events. In contrast, untreated thymocytes had bright cytochrome $c$ staining, large diffuse nuclei, and only $5 \%$ of the untreated thymocytes exhibited fragmented DNA (Fig. $6 E$ and $F$ ).

Ligation of CD8 by MHC Class I Molecules Induces Apoptosis. Because ligation of CD8 with antibodies was able to induce apoptosis, we examined whether the natural ligand of CD8 MHC class I molecules induced a similar effect. Thymocytes from an $\mathrm{MHC}^{-/-}$mouse were treated with microspheres coated with classical $\left(\mathrm{H}-2 \mathrm{~K}^{\mathrm{b}}\right)$ or nonclassical MHC class I molecules (TL). After 30 min of incubation with the MHC class I-coated microspheres, $25-30 \%$ of the thymocytes were apoptotic (Fig. 2). This number is comparable with the number of apoptotic cells $(25 \%)$ observed after a 30-min incubation with biotinylated anti-CD8 

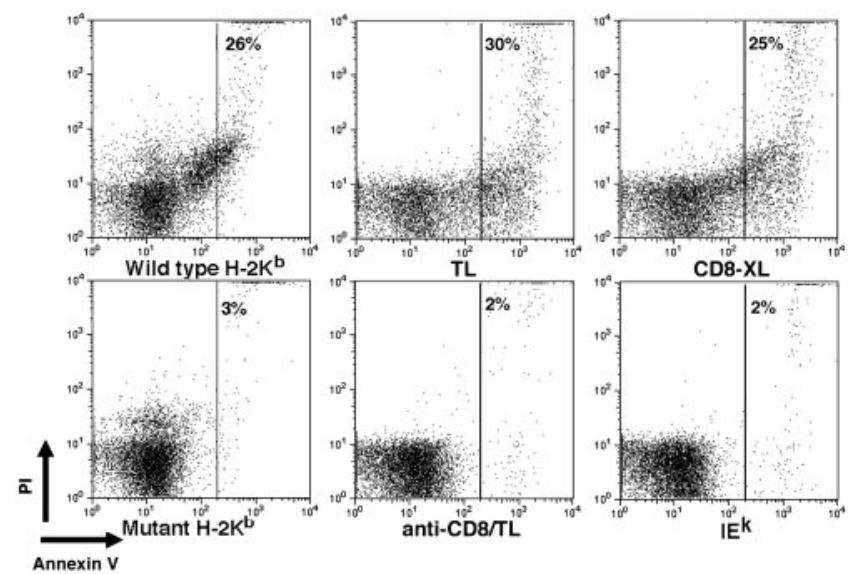

Fig. 2. Ligation of $\mathrm{CD} 8$ with $\mathrm{TL}$ or $\mathrm{H}-2 \mathrm{~K}^{\mathrm{b}}$ induces apoptosis. Thymocytes from $\mathrm{MHC}^{-1-}$ mice were treated with microspheres coated with wild-type $\left(\mathrm{H}-2 \mathrm{~K}^{\mathrm{b}}\right)$ or mutant $\left(\mathrm{H}-2 \mathrm{~K}^{\mathrm{b}}\right.$ Lys-227) $\mathrm{H}-2 \mathrm{~K}^{\mathrm{b}}$ molecules; microspheres coated with $\mathrm{TL}$ molecules either in the absence (TL) or presence of CD8-blocking antibody (anti-CD8/TL); biotinylated antibody to CD8a and streptavidin-coated microspheres (CD8-XL); or microspheres coated with $\mathrm{IE}^{\mathrm{k}}$ for $30 \mathrm{~min}$. Cells were stained with FITC-annexin V and PI. Annexin V binding is shown on the $x$ axis, and $\mathrm{PI}$ staining is shown on the $y$ axis. The number in each plot represents the percentage of cells in the gate.

and streptavidin-coated beads. Streptavidin-conjugated beads that were coated with mutant $\mathrm{H}-2 \mathrm{~K}^{\mathrm{b}}$ Lys-227 molecules that cannot bind CD8 (16) failed to induce apoptosis, indicating that the induction of apoptosis depended on the binding of $\mathrm{H}-2 \mathrm{~K}^{\mathrm{b}}$ to CD8. Further evidence that the induction of apoptosis by $\mathrm{MHC}$ class I molecules depended on binding to CD8 was provided by the observation that the apoptosis induced by the TL-coated beads was completely blocked by pretreatment with antibody to CD8 $\alpha$ (YTS169) under noncrosslinking conditions. Streptavidin-conjugated beads that were coated with MHC class II (IEk) molecules or uncoated microspheres did not induce apoptosis and resembled the untreated sample. Interestingly, we were unable to induce apoptosis with tetrameric MHC class I molecules (data not shown), indicating that an optimal amount of crosslinking may be required to stimulate apoptosis.

CD8-Mediated Apoptosis Is Developmentally Regulated. We compared the induction of CD8-mediated apoptosis in thymocytes from wild-type mice and mice in which $\mathrm{T}$ cell development is arrested. Antibody-mediated ligation of CD8 on thymocytes from B6 mice induced apoptosis in $\approx 20 \%$ of the cells (Fig. $3 A$ ). In $\mathrm{MHC}^{-1-}$ mice, the number of thymocytes that were apoptotic after antibody crosslinking of CD8 was greater (35\%) than in normal mice. Crosslinking of CD8 did not induce apoptosis in $\mathrm{CD}^{+} \mathrm{SP}$ thymocytes or peripheral $\mathrm{CD} 8^{+} \mathrm{T}$ cells (data not shown). Ligation of CD8 with TL-coated microspheres induced similar levels of apoptosis compared with the antibody-mediated crosslinking in both B6 and $\mathrm{MHC}^{-/-}$thymocytes (Fig. $3 B$ ). These observations demonstrate that thymocytes that are susceptible to CD8-mediated apoptosis are more abundant in mice in which thymocyte development is arrested at a stage before positive selection. This result suggests that in wild-type mice the susceptibility to CD8-mediated apoptosis might be a characteristic of DP thymocytes that have not yet undergone positive selection.

The easiest approach to determine whether the susceptible thymocytes in wild-type mice had undergone positive selection would be to compare the surface phenotype of the annexin $\mathrm{V}^{+}$and annexin $\mathrm{V}^{-}$cells in cultures treated with antibody to CD8. However, treatment with antibody to CD8 under crosslinking conditions caused changes in the surface phenotype of the thymocytes. There-
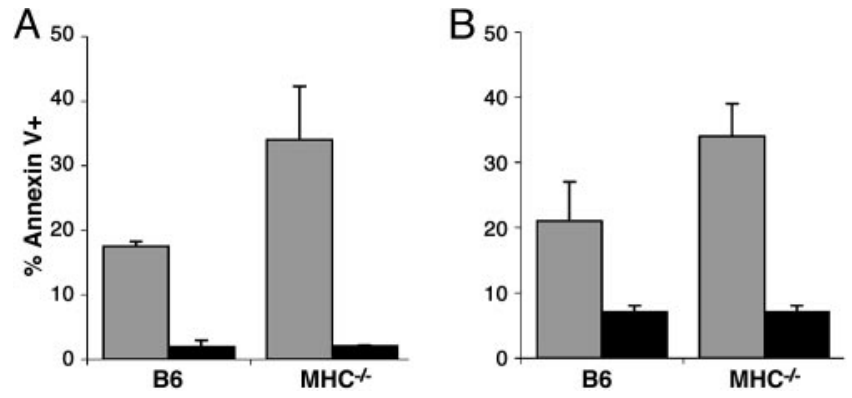

Fig. 3. CD8-mediated apoptosis is developmentally regulated. Thymocytes from $\mathrm{B} 6$ or $\mathrm{MHC}^{-1-}$ mice were incubated with antibody to $\mathrm{CD} 8$ under crosslinking conditions or beads were coated with MHC class I molecules (gray bars) or were left untreated (black bars), and stained with FITC-annexin V and PI. The percentage of annexin ${ }^{+}$cells was determined by flow cytometry. The error bars represent the SD of at least three mice per group. $(A)$ Thymocytes were treated with antibody to $\operatorname{CD} 8 \alpha$ and goat anti-rat Ig for $6 \mathrm{~h}$. (B) Thymocytes were treated with TL-coated microspheres for $30 \mathrm{~min}$.

fore, it was not possible to determine the phenotype of the susceptible cells directly in the cultures treated with antibody to CD8. To identify the surface phenotype of the susceptible cells, thymocytes from wild-type mice were sorted into distinct subsets defined by their surface phenotype. Sorting the populations also allowed for equal numbers of thymocytes of each phenotype to be compared. DP thymocytes that have not completed positive selection are $\mathrm{CD} 2^{\mathrm{lo}}, \mathrm{CD}^{\mathrm{lo}}$, and $\mathrm{CD} 69^{-}$, whereas cells that pass positive selection are $\mathrm{CD} 2^{\mathrm{hi}}, \mathrm{CD} 5^{\mathrm{hi}}$, and $\mathrm{CD} 69^{+}$. Cells that expressed CD4 and $\mathrm{CD} 8 \beta$ were separated into populations that were "prepositive" $\left(\mathrm{CD} 2^{\mathrm{lo}} \mathrm{CD} 5^{\text {lo }} \mathrm{CD} 69^{-}\right)$and "postpositive" $\left(\mathrm{CD} 2^{\text {hi }} \mathrm{CD} 5^{\text {hi }} \mathrm{CD} 69^{+}\right)$ selection. These populations were then cultured with biotinylated antibody to CD $8 \alpha$ and streptavidin-coated microspheres for $30 \mathrm{~min}$, and binding of annexin V-FITC was measured by flow cytometry. The proportion of apoptotic cells was greatly enriched in the populations that expressed markers consistent with a prepositive selection phenotype compared with the postpositive selection phenotype (Fig. 4). Therefore, in normal mice, DP thymocytes that have not undergone positive selection are much more susceptible to CD8-mediated apoptosis than to postpositive-selection DP thymocytes.

CD3 Stimulation Protects Thymocytes from CD8-Mediated Apoptosis. Because the population of thymocytes susceptible to CD8mediated apoptosis had not been positively selected, we examined whether stimulation through TCR/CD 3 could protect these thymocytes from CD8-mediated apoptosis. Thymocytes from $\mathrm{MHC}^{-1-}$ mice were incubated with biotinylated antibodies to both $\mathrm{CD} 8 \alpha$ and CD3 and were cocrosslinked with streptavidincoated microspheres for $30 \mathrm{~min}$. Whereas $25 \%$ of the thymocytes were apoptotic with CD8 crosslinking alone, cocrosslinking of $\mathrm{CD} 8$ and $\mathrm{CD} 3$ reduced the number of apoptotic cells to $\approx 10 \%$ (Fig. 5). Treatment of thymocytes with antibody to CD8 and a control biotinylated antibody (R4GA2) did not reduce the number of apoptotic thymocytes compared with CD8 crosslinking alone, indicating that the effect of antibody to CD3 was not simply due to a reduction in the extent of CD8 crosslinking. Also, treatment of thymocytes with phorbol myristate acetate (PMA), which mimics some TCR signals by activation of PKC, also inhibited the induction of apoptosis by crosslinking of CD8. Crosslinking of CD3 or treatment with PMA alone did not induce apoptosis in $30 \mathrm{~min}$. Therefore, whereas CD8 ligation in the absence of TCR/CD3 engagement results in apoptosis, engagement of both CD8 and TCR/CD3 results in survival. This finding suggests that thymocytes that express a TCR that can engage MHC molecules and be positively selected may be protected from CD8-mediated apoptosis. 

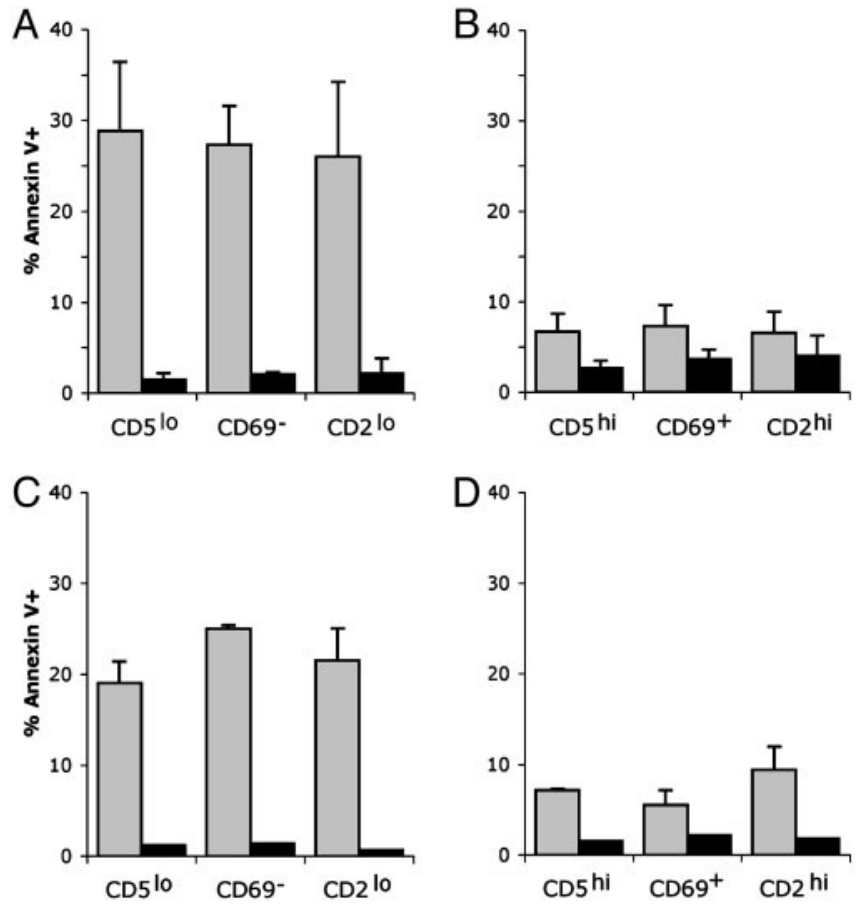

Fig. 4. Thymocytes susceptible to CD8-mediated apoptosis are prepositive selection. DP thymocytes from C57BL/ 6 mice were sorted based on either CD5, CD69, or CD2 expression. Cells were incubated with antibody to CD8 under crosslinking conditions or beads were coated with MHC class I molecules (gray bars) or were left untreated (black bars) for $30 \mathrm{~min}$. Cells were stained with FITC-annexin $\mathrm{V}$ and the percentage of annexin ${ }^{+}$cells was determined by flow cytometry. The error bars represent the SD of at least three mice per group. (A) Prepositive selection-sorted cells $\left(\mathrm{CD}^{\mathrm{lo}} ; \mathrm{CD}_{69^{-}}\right.$; and $\left.\mathrm{CD} 2^{\mathrm{lo}}\right)$ stimulated with biotinylated antibody to CD8 and streptavidin-coated microspheres. ( $B$ ) Postpositive selection-sorted cells (CD5 $5^{\text {hi }}$, $\mathrm{CD}_{69}{ }^{+}$; and $\left.\mathrm{CD} 2^{\text {hi }}\right)$ stimulated with biotinylated antibody to CD8 and streptavidin-coated microspheres. (C) Prepositive selection-sorted cells stimulated with TL-coated microspheres. (D) Postpositive selection-sorted cells stimulated with TL-coated microspheres.

\section{Discussion}

We have demonstrated that ligation of CD8 on immature DP thymocytes, in the absence of TCR engagement, results in apoptosis. The ligation of CD8 can be achieved either by antibody crosslinking or by the binding of the natural ligand for CD8 MHC class I molecules. The interaction between the TL-coated microspheres and the thymocytes was mediated by CD8 and not by TCR, because blocking antibody (i.e., under noncrosslinking conditions) to CD8 inhibited the interaction and prevented apoptosis of thymocytes. Also, mutant $\mathrm{H}-2 \mathrm{~K}^{\mathrm{b}}$ (Lys ${ }^{227}$ ) molecules that cannot interact with CD8 were unable to induce apoptosis. These observations suggest that the induction of apoptosis by MHC class I molecules was mediated through binding to CD8 molecules.

CD8-mediated apoptosis is developmentally regulated. The proportion of thymocytes susceptible to CD8-mediated apoptosis is increased in $\mathrm{MHC}^{-/-}$mice in which thymocyte development is arrested in the DP stage before positive selection. The surface phenotype of the susceptible thymocytes resembles that of a population that is prepositive selection. This population expresses low levels of CD5 and CD2, indicating that these cells have not received a signal through TCR or passed through positive selection $(17,18)$. The failure to express CD69 is also consistent with these cells being at the prepositive selection stage (19-21). Overall, these observations are consistent with CD8mediated apoptosis being a mechanism for the deletion of cells that do not survive positive selection.

Previous studies $(14,15)$ have shown that DP thymocytes can bind MHC class I tetramers in a TCR-independent fashion. DP thymocytes express CD8 molecules that are not extensively sialylated and have a high affinity for MHC class I molecules compared with the sialylated form of CD8 expressed on SP thymocytes and peripheral T cells. The higher affinity of CD8 for MHC class I molecules enables it to bind MHC class I molecules in the absence of TCR engagement. The significance of this interaction is not established. Other groups have hypothesized that the high-affinity form of CD8 may enhance thymocyte adhesion to thymic epithelial cells and therefore enhance positive selection $(14,15)$. The population of DP thymocytes that
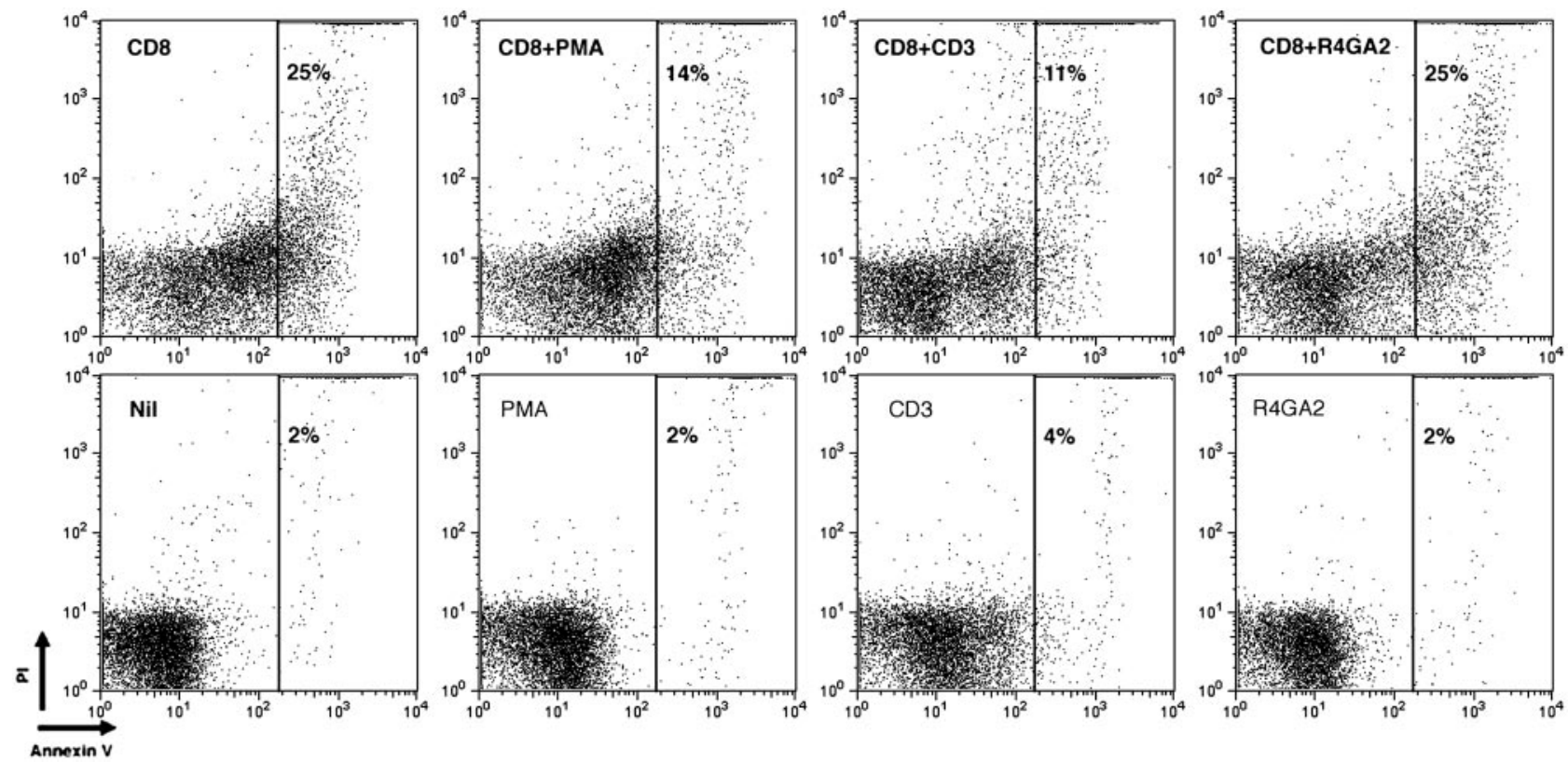

Fig. 5. PMA or CD3 crosslinking reduces CD8-mediated apoptosis. Thymocytes from $\mathrm{MHC}^{-1-}$ mice were treated with biotinylated antibody to $\mathrm{CD} 8$ and streptavidin-coated microspheres or were left untreated (nil) for $30 \mathrm{~min}$. Thymocytes were also treated with PMA, biotinylated anti-CD3, or a biotinylated control antibody (R4GA2) with and without CD8-crosslinking. Annexin V binding is shown on the $x$ axis, and PI staining is shown on the $y$ axis. In each plot, the percentage of cells in the gate is given. 
binds tetrameric MHC class I molecules through CD8 in a TCR-independent manner includes the subpopulation susceptible to CD8-mediated apoptosis. Some of the postpositive selection $\left(\mathrm{CD}^{\circ} 9^{+}\right) \mathrm{DP}$ thymocytes can still bind beads coated with MHC class I molecules and also PNA, indicating that the high-affinity (desialylated) form of CD8 is still expressed on these cells; however, they do not undergo CD8 mediated apoptosis. Therefore, although the expression of the high-affinity form of $\mathrm{CD} 8$ is required for the binding of MHC class I molecules, it is not the only factor contributing to the susceptibility to CD8-mediated apoptosis. This result is even more apparent in the experiments using antibodies to CD8 to induce apoptosis. Even though the antibody to CD8 binds to mature DP and SP thymocytes, and also to peripheral $\mathrm{T}$ cells, apoptosis initiated by antibody crosslinking of CD8 is confined to immature DP thymocytes (Fig. 4, and Fig. 7, which is published as supporting information on the PNAS web site). Thus, the signaling events downstream of CD8 ligation probably undergo stage-specific changes and regulates susceptibility to CD8mediated apoptosis.

Here, we demonstrate that cocrosslinking of CD3 with CD8 prevents apoptosis. This observation is consistent with a model in which thymocytes that engage CD8 in the absence of engagement of TCR/CD3 are susceptible to death. Thymocytes that express a functional TCR that engages MHC molecules "passes" positive selection and would not receive this apoptotic signal through CD8. Thymocytes that have begun positive selection may be resistant to CD8-mediated apoptosis because expression of Bcl-2 is increased after positive selection (22). Treatment with PMA also prevented CD8-mediated apoptosis. The major effect of PMA on cells is the activation of $\mathrm{PKC}(23)$. PKC $\theta$ phosphorylates the $\mathrm{Bcl}-2$ family member BAD on Ser-112 after TCR stimulation $(24,25)$. The phosphorylation of BAD prevents it from binding and inhibiting Bcl-2. The activation of PKCs can also stimulate the Ras/mitogenactivated protein kinase cascade including the extracellular signalregulated kinase (Erk) pathway. Upon activation by Erk, the p90 ribosomal S6 kinase (p90 RSK) can also phosphorylate BAD on Ser-112 (24, 26-28). Interestingly, the Erk pathway has been implicated in positive selection (29), and positive selection is blocked in Erk-1 knockout mice (30).

Previous studies (31) have established that there is a population of DP thymocytes that are refractory to stimulation through their TCR. Incubation with antibodies to CD3 in fetal thymic organ culture induces apoptosis of a proportion of DP thymocytes after $18 \mathrm{~h}$ of culture (32); however, phenotype of the cells that undergo apoptosis was not fully characterized. In contrast to the in vivo studies, engagement of the TCR with antibodies in vitro is insufficient to induce the death of DP thymocytes (33), and engagement of CD28 along with CD3 is required to induce apoptosis in vitro $(34,35)$. We do not observe any apoptosis after $6 \mathrm{~h}$ of crosslinking CD3 with biotinylated anti-CD3 and streptavidin-coated microspheres (data not shown).

Almost 20 years ago (36), it was suggested that engagement of CD4 or CD8 by antibodies in the absence of TCR delivered a "negative signal" to the $\mathrm{T}$ cell such that subsequent ligation through the TCR was unable to activate the T cell. Numerous studies have confirmed this observation by using antibodies to CD4 (37) or other ligands of CD4 [such as HIV gp120 or IL-16 (38)]. The mechanism by which CD4 ligation inhibits TCR

1. Berg, L. J., Pullen, A. M., Fazekas de St. Groth, B., Mathis, D., Benoist, C. \& Davis, M. M. (1989) Cell 58, 1035-1046.

2. Ashton-Rickardt, P. G., Bandeira, A., Delaney, J. R., Van Kaer, L., Pircher, H. P., Zinkernagel, R. M. \& Tonegawa, S. (1994) Cell 76, 651-663.

3. Alam, S. M., Travers, P. J., Wung, J. L., Nasholds, W., Redpath, S., Jameson, S. C. \& Gascoigne, N. R. (1996) Nature 381, 616-620.

4. Jenkinson, E. J., Kingston, R., Smith, C. A., Williams, G. T. \& Owen, J. J. (1989) Eur. J. Immunol. 19, 2175-2177. signaling is unclear. Some studies indicate that the mechanism for this negative signaling is the sequestration of p56lck away from the TCR (39); however, other studies have indicated that CD4 mediated signaling is more than simply p56lck sequestration. The aggregation of CD 4 by HIV gp120 or IL-16 also inhibits $\mathrm{T}$ cell proliferation to antigens or mitogens and promotes apoptosis (reviewed in ref. 40).

We found that antibody-mediated crosslinking of CD4 or MHC class II beads did not induce apoptosis of thymocytes. There is no evidence that CD4 undergoes developmentally regulated changes in the affinity for MHC class II molecules such that it can bind to MHC class II molecules in the absence of TCR engagement. A number of studies $(14,15,41-43)$ have provided evidence that there are differences in the roles of CD4 and CD8 during the development and maturation of thymocytes. These differences may be related to both the differences in the affinity for MHC molecules and differences in the association with intermediates of particular signaling pathways. It is possible that, in DP thymocytes, ligation of CD4 and CD8 results in the activation of different signaling pathways. In DP thymocytes, the association of p56lck with CD4 is greater than its association with CD8 (44), but LAT (linker of activated T cells) is preferentially associated with CD8, rather than CD4 (41). Differences in the role of CD4 and CD8 signaling during lineage commitment have been readily observed (reviewed in ref. 45).

Cytokine withdrawal and death receptors have been implicated in removing cells that cannot be positively selected. It is possible that both of these pathways are involved and that they actually are overlapping or redundant pathways. This possibility may also be the case for the apoptotic death of thymocytes that we describe herein. CD8-mediated apoptosis may be a mechanism to facilitate death of thymocytes that cannot survive positive selection; however, in its absence, other pathways such as those initiated by cytokine withdrawal, can lead to the removal of cells that fail positive selection. There is no overt accumulation of thymocytes in $\beta_{2} \mathrm{~m}^{-1-}, \mathrm{CD}^{-1-}$, or $\mathrm{MHC}^{-/-}$mice, suggesting that CD8-mediated apoptosis is not the only mechanism by which thymocytes that fail positive selection are removed. This situation is similar to negative selection in which multiple apoptotic mechanisms have been implicated. By analogy, it would not be surprising if there were multiple pathways that are able to delete cells that cannot be positively selected.

In summary, we have shown that ligation of CD8 molecules on immature DP thymocytes, in the absence of TCR engagement, results in rapid apoptosis. The population of thymocytes susceptible to CD8-mediated apoptosis is prepositive selection and stimulation through CD3 rescues them from death. Engagement of the highaffinity form of CD8 on DP thymocytes by MHC class I molecules may have multiple roles. It may enhance thymocyte interactions with thymic epithelial cells during positive selection; however, if CD8 is engaged in the absence of TCR it can lead to apoptosis. Therefore, thymocytes that are not positively selected may be instructed to die instead of being deleted by mere neglect.

We thank Fran Crawford, Rachel Fruge, and Drs. John Kappler and Rick Willis for their help in producing the soluble class I and class II molecules; Dr. Nathalie Pardigon for the full-length TL construct; Drs. John Routes and Jill Slansky for helpful criticism of this manuscript; and Drs. Philippa Marrack, John Kappler, James DeGregori, Uwe Staerz, and John Cambier for helpful discussions.

5. Akbar, A. N., Borthwick, N. J., Wickremasinghe, R. G., Panayoitidis, P., Pilling, D., Bofill, M., Krajewski, S., Reed, J. C. \& Salmon, M. (1996) Eur. J. Immunol. 26, 294-299.

6. Miyazaki, T., Liu, Z. J., Kawahara, A., Minami, Y., Yamada, K., Tsujimoto, Y., Barsoumian, E. L., Permutter, R. M. \& Taniguchi, T. (1995) Cell 81, 223-231.

7. von Freeden-Jeffry, U., Solvason, N., Howard, M. \& Murray, R. (1997) Immunity 7, 147-154. 
8. Zornig, M., Hueber, A. O. \& Evan, G. (1998) Curr. Biol. 8, 467-470.

9. Jaffe, H. (1924) J. Exp. Med. 40, 753-759.

10. Brewer, J. A., Kanagawa, O., Sleckman, B. P. \& Muglia, L. J. (2002) J. Immunol. 169, 1837-1843.

11. Boursier, J. P., Alcover, A., Herve, F., Laisney, I. \& Acuto, O. (1993) J. Biol. Chem. 268, 2013-2020.

12. Casabo, L. G., Mamalaki, C., Kioussis, D. \& Zamoyska, R. (1994) J. Immunol. 152, 397-404.

13. Priatel, J. J., Chui, D., Hiraoka, N., Simmons, C. J., Richardson, K. B., Page, D. M., Fukuda, M., Varki, N. M. \& Marth, J. D. (2000) Immunity 12, 273-283.

14. Moody, A. M., Chui, D., Reche, P. A., Priatel, J. J., Marth, J. D. \& Reinherz, E. L. (2001) Cell 107, 501-512.

15. Daniels, M. A., Devine, L., Miller, J. D., Moser, J. M., Lukacher, A. E., Altman, J. D., Kavathas, P., Hogquist, K. A. \& Jameson, S. C. (2001) Immunity 15, 1051-1061.

16. Potter, T. A., Rajan, T. V., Dick, R. F. d. \& Bluestone, J. A. (1989) Nature 337, 73-75.

17. Duplay, P., Lancki, D. \& Allison, J. P. (1989) J. Immunol. 142, 2998-3005.

18. Tarakhovsky, A., Kanner, S. B., Hombach, J., Ledbetter, J. A., Muller, W., Killeen, N. \& Rajewsky, K. (1995) Science 269, 535-537.

19. Swat, W., Dessing, M., von Boehmer, H. \& Kisielow, P. (1993) Eur. J. Immunol. 23, 739-746.

20. Brandle, D., Muller, S., Muller, C., Hengartner, H. \& Pircher, H. (1994) Eur. J. Immunol. 24, 145-151.

21. Yamashita, I., Nagata, T., Tada, T. \& Nakayama, T. (1993) Int. Immunol. 5, 1139-1150.

22. Gratiot-Deans, J., Merino, R., Nunez, G. \& Turka, L. A. (1994) Proc. Natl. Acad. Sci. USA 91, 10685-10689.

23. Nishizuka, Y. (1984) Nature 308, 693-698.

24. Tan, Y., Ruan, H., Demeter, M. R. \& Comb, M. J. (1999) J. Biol. Chem. 274 34859-34867.

25. Villalba, M., Bushway, P. \& Altman, A. (2001) J. Immunol. 166, 5955-5963.

26. Fisher, T. L. \& Blenis, J. (1996) Mol. Cell. Biol. 16, 1212-1219.

27. Bertolotto, C., Maulon, L., Filippa, N., Baier, G. \& Auberger, P. (2000) J. Biol. Chem. 275, 37246-37250.
28. Bonni, A., Brunet, A., West, A. E., Datta, S. R., Takasu, M. A. \& Greenberg, M. E. (1999) Science 286, 1358-1362.

29. Alberola-Ila, J. \& Hernandez-Hoyos, G. (2003) Immunol. Rev. 191, 79-96.

30. Pages, G., Guerin, S., Grall, D., Bonino, F., Smith, A., Anjuere, F., Auberger, P. \& Pouyssegur, J. (1999) Science 286, 1374-1377.

31. Finkel, T. H., Cambier, J. C., Kubo, R. T., Born, W. K., Marrack, P. \& Kappler, J. W. (1989) Cell 58, 1047-1054

32. Smith, C. A., Williams, G. T., Kingston, R., Jenkinson, E. J. \& Owen, J. J. (1989) Nature 337, 181-184

33. Page, D. M., Kane, L. P., Allison, J. P. \& Hedrick, S. M. (1993) J. Immunol. 151, 1868-1880.

34. Punt, J. A., Osborne, B. A., Takahama, Y., Sharrow, S. O. \& Singer, A. (1994) J. Exp. Med. 179, 709-713.

35. Kishimoto, H. \& Sprent, J. (1999) J. Exp. Med. 190, 65-73.

36. Bank, I. \& Chess, L. (1985) J. Exp. Med. 162, 1294-1303.

37. Newell, M. K., Haughn, L. J., Maroun, C. R. \& Julius, M. H. (1990) Nature 347, 286-289.

38. Cruikshank, W. W., Kornfeld, H. \& Center, D. M. (1998) Int. Rev. Immunol. 16, 523-540.

39. Haughn, L., Gratton, S., Caron, L., Sekaly, R. P., Veillette, A. \& Julius, M. (1992) Nature 358, 328-331.

40. Casella, C. R. \& Finkel, T. H. (1997) Curr. Opin. Hematol. 4, 24-31.

41. Bosselut, R., Zhang, W., Ashe, J. M., Kopacz, J. L., Samelson, L. E. \& Singer, A. (1999) J. Exp. Med. 190, 1517-1526.

42. Brugnera, E., Bhandoola, A., Cibotti, R., Yu, Q., Guinter, T. I., Yamashita, Y., Sharrow, S. O. \& Singer, A. (2000) Immunity 13, 59-71.

43. Moody, A. M., Xiong, Y., Chang, H. C. \& Reinherz, E. L. (2001) Eur. J. Immunol. 31, 2791-2799.

44. Wiest, D. L., Yuan, L., Jefferson, J., Benveniste, P., Tsokos, M., Klausner, R. D., Glimcher, L. H., Samelson, L. E. \& Singer, A. (1993) J. Exp. Med. 178, $1701-1712$

45. Germain, R. N. (2002) Nat. Rev. Immunol. 2, 309-322. 